\title{
THE POTENTIAL OF VACUUM ULTRAVIOLET PHOTOIONIZATION MASS SPECTROMETRY IN MONITORING PHOTOFRAGMENTATION OF ORGANOMETALLICS
}

\author{
S. GEORGIOU, E. MASTORAKI, E. RAPTAKIS, Z. XENIDI \\ Foundation for Research and Technology-Hellas Institute of Electronic \\ Structure and Laser, P.O. Box 1527, GR 71110 Heraklion, Crete, Greece
}

(Received 10 October, 1992)

The paper examines the potential of vacuum ultraviolet (VUV) photoionization mass spectroscopy in probing the fragmentation of organometallics in molecular-beam studies and laser-assisted deposition processes. To this end, the ionic fragmentation pattern of few common organometallics, namely metallocenes and carbonyls, is examined at selected VUV wavelengths, produced by microwave-discharge resonance atomic lamps. Discussion of the recorded spectra in terms of the electronic structure of the compounds indicates lack of dynamical bias in the VUV photoionization/fragmentation of metal complexes. Excitation with VUV light results in simpler ionic fragmentation patterns than what observed with electron-impact ionization, thereby enabling accurate monitoring of the excimer-laser photodissociation of organometallics. Finally, the intensity of the VUV ionic signal appears to be adequate for molecular-beam studies. An illustrative example is provided for the study of the $248 \mathrm{~nm}$-induced photodesorption of $\mathrm{Mo}(\mathrm{CO})_{6}$ from cryogenic films.

KEY WORDS: Vacuum Ultraviolet-Photoionization-Fragmentation-Organometallics

\section{INTRODUCTION}

The investigation of the photolysis of organometallics is of fundamental interest (e.g., for learning about the nature of bonding by metals ${ }^{1}$ ) and of technological importance as well (e.g., for the optimization of laser-induced metal deposition processes on surfaces, ${ }^{2}$ of photocatalysis ${ }^{3}$ etc.). A number of experimental techniques ${ }^{1}$ have been used to interrogate the photolysis of organometallic compounds and in particular, to establish their fragmentation pattern obtained upon excitation with excimer-laser light.

Of the employed techniques, time-resolved infrared absorption spectroscopy has been particularly successful ${ }^{1 \mathrm{~b}-\mathrm{c}}$ in establishing the character of the photolysis products. However, the determination of the product yield is at best qualitative, because the infrared absorption cross-sections in the unsaturated $\mathrm{M}(\mathrm{CO}) \mathrm{x}$ species are unknown. Thus, the photodissociation dynamics and the details of the mechanism are addressed only indirectly. Additionally, the technique suffers from the low spectral resolution of line tunable lasers, difficulties in assigning IR bands to specific 
organometallic fragments and from limited applicability, being best suited to the study of organometallic carbonyls.

In contrast, direct and detailed information on molecular photodissociation is usually possible from molecular beam studies ${ }^{4}$ (electron-impact photofragment spectroscopy). In these experiments, the photoproduct distribution is determined by monitoring the molecular ions that are formed by electron impact in a mass spectrometer. Unfortunately, in the case of organometallics, the bonds are quite weak and electron-impact ionization results in extensive fragmentation. Consequently, the recorded signals represent both molecular ions of the primary photofragments, and also secondary ions (i.e., that have suffered ligand loss(es)) from the electron borbardment on the excimer-induced primary photofragments. Given the multitude of fragments formed in the photolysis of organometallics, sorting out the origin of the observed ions introduces considerable difficulties and uncertainties. Therefore, the determination of the nature and yield of the photolysis products can be highly inaccurate.

Evidently, a more reliable and accurate detection technique would be of much help to the study of the organometallic photophysics. Furthermore, a relatively simple technique is much needed for the in-situ monitoring of laser-induced chemical vapor deposition (LCVD) processes employing organometallics as metal atom precursors.

A promising alternative approach to the probing of organometallics may be afforded by VUV photoionization. Photoionization just aboye the vertical ionization potential avoids most complications introduced by electron-impact techniques, namely extensive fragmentation and uncertainties about the electron energy distribution. Since most organometallics and metalloids have ionization potentials below $10 \mathrm{eV}$, the required light can be easily obtained from microwave-discharge atomic resonance lamps.

Our purpose in this report is to examine if VUV ionization can effect ionization of metal complexes with minimal fragmentation and with adequate signal-to-noise ratio for implementation in photodissociation molecular-beam studies and LCVD processes. To this end, we examine the ionic fragmentation patterns that common organometallics and metalloid compounds yield upon VUV irradiation. The patterns are related with the electronic structure of the molecules. Furthermore, the potential of the approach in monitoring the excimer-laser photolysis of organometallics is discussed.

\section{EXPERIMENTAL}

The main experimental setup has been described before. ${ }^{1 \mathrm{e}}$ Briefly, it consists of a six-way stainless-steel cross housing a quadrupole mass-spectrometer (Balzers QMG 312 or 412). The cell is continuously evacuated by a turbomolecular pump to a base pressure of approximately $2 \times 10^{-6} \mathrm{~Pa}$. The compounds are introduced through a leak-valve to establish a pressure of about $2 \times 10^{-3} \mathrm{~Pa}$. Pressure readings have not been corrected for the slightly different sensitivity of the gauge to the various compounds. 
The VUV light is produced by microwave discharge ( 40 to $70 \mathrm{~W}$ of $2450 \mathrm{~Hz}$ power from a Microtron 200 III generator delivered to an Evenson-Broida cavity ${ }^{5}$ ) in gas mixtures flowing through a lamp of a design similar to that of Okabe. ${ }^{6}$ The lamp ( $12 \mathrm{~mm}$ o.d.) is mounted to one of the window ports of the photofragmentation cell by means of an ultratorr adaptor welded to a flange. The absolute intensity of the lamps is measured by monitoring the fluorescence from a sodium salicylatecoated window placed opposite to the VUV lamp. The employed gases include $2 \%$ $\mathrm{H}_{2}$ in $\mathrm{He}$ (emitting at $121.57 \mathrm{~nm}$ ), $3 \% \mathrm{Kr}$ (at $116.49 \mathrm{~nm}$ and $123.58 \mathrm{~nm}$, the latter being isolated with a $\mathrm{LiF}$ window), $3 \% \mathrm{Xe}$ (at $146.96 \mathrm{~nm}$ with $\mathrm{BaF}_{2}$ window), and $1 \% \mathrm{~N}_{2}(149.27 \mathrm{~nm}, 149.47 \mathrm{~nm}, 174.27 \mathrm{~nm}$ and $174.52 \mathrm{~nm}){ }^{7}$ The emission lines of the lamps have not been ascertained, but every precaution has been taken to ensure the purity of the employed mixtures and the minimization of emitting by-products.

\section{RESULTS}

Table 1 presents the studied compounds along with the ions that are produced upon excitation with the different lamps. The specific compounds were chosen for examination, firstly, because they have been the subject of several photodissociation studies, and, secondly, because of their technological importance in LCVD processes. In those cases that more than one ion is formed, the last column of the Table gives the intensity (measured as peak height) of the daughter ion(s) normalized to the corresponding parent ion peak.

Table 1 Fragmentation pattern of organometallic compounds upon VUV excitation.

\begin{tabular}{|c|c|c|c|c|}
\hline Compound & $\begin{array}{l}\text { Ionization } \\
\left.\text { Potential }(\mathrm{eV})^{\mathrm{a}}\right)\end{array}$ & $\begin{array}{l}\text { Excitation } \\
\text { Energy }(\mathrm{eV})\end{array}$ & Fragments & $\begin{array}{l}\text { Fragment } \\
\text { Percentage }\end{array}$ \\
\hline$\left(\mathrm{C}_{5} \mathrm{H}_{5}\right)_{2} \mathrm{Ni}$ & $6.51^{11}$ & $\begin{array}{l}10.64 \\
10.20 \\
10.03\end{array}$ & $\begin{array}{l}\left(\mathrm{C}_{5} \mathrm{H}_{5}\right)_{2} \mathrm{Ni}^{+} \\
\left(\mathrm{C}_{5} \mathrm{H}_{5}\right)_{2} \mathrm{Ni}^{+} \\
\left(\mathrm{C}_{5} \mathrm{H}_{5}\right)_{2} \mathrm{Ni}^{+}\end{array}$ & \\
\hline$\left(\mathrm{C}_{5} \mathrm{H}_{5}\right)_{2} \mathrm{Co}$ & $5.56^{12}$ & 10.20 & $\left(\mathrm{C}_{5} \mathrm{H}_{5}\right)_{2} \mathrm{Co}^{+}$ & \\
\hline$\left(\mathrm{C}_{5} \mathrm{H}_{5}\right)_{2} \mathrm{Fe}$ & $6.86^{11}$ & 10.20 & $\begin{array}{l}\left(\mathrm{C}_{5} \mathrm{H}_{5}\right)_{2} \mathrm{Fe}^{+} \\
\left(\mathrm{C}_{5} \mathrm{H}_{5}\right) \mathrm{Fe}^{+}\end{array}$ & $\begin{array}{l}1 \\
0.4\end{array}$ \\
\hline$\left(\mathrm{C}_{5} \mathrm{H}_{5}\right) \mathrm{Ni}(\mathrm{NO})$ & $8.50^{13}$ & $\begin{array}{l}10.64 \\
10.20 \\
10.03\end{array}$ & $\begin{array}{l}\left(\mathrm{C}_{5} \mathrm{H}_{5}\right) \mathrm{Ni}(\mathrm{NO})^{+} \\
\left(\mathrm{C}_{5} \mathrm{H}_{5}\right) \mathrm{Ni}^{+} \\
\left(\mathrm{C}_{5} \mathrm{H}_{5}\right) \mathrm{Ni}(\mathrm{NO})^{+} \\
\left(\mathrm{C}_{5} \mathrm{H}_{5}\right) \mathrm{Ni}(\mathrm{NO})^{+}\end{array}$ & $\begin{array}{l}1 \\
0.3\end{array}$ \\
\hline $\mathrm{Co}(\mathrm{CO})_{3}(\mathrm{NO})$ & $8.90^{14}$ & 10.64 & $\begin{array}{l}\mathrm{Co}(\mathrm{CO})_{3}(\mathrm{NO})^{+} \\
\mathrm{Co}(\mathrm{CO})_{2}(\mathrm{NO})^{+}\end{array}$ & $\begin{array}{l}1 \\
0.2\end{array}$ \\
\hline $\mathrm{Cr}(\mathrm{CO})_{6}$ & $8.42^{15}$ & $\begin{array}{l}10.20 \\
10.64\end{array}$ & $\begin{array}{l}\mathrm{Co}(\mathrm{CO})_{3}(\mathrm{NO})^{+} \\
\mathrm{Cr}(\mathrm{CO})^{+}\end{array}$ & $\begin{array}{l}1 \\
1\end{array}$ \\
\hline & & & $\mathrm{Cr}(\mathrm{CO})_{5}^{+}$ & $0.2^{\mathrm{b}}$ \\
\hline $\mathrm{Mo}(\mathrm{CO})_{6}$ & $8.2^{16}$ & 10.64 & $\mathrm{Mo}(\mathrm{CO})_{6}^{+}$ & \\
\hline
\end{tabular}

a) Vertical ionization potential

b) Peak very small for accurate measurement. 
Inspection of the Table indicates that the fragmentation pattern depends on the nature of the compound. For $\mathrm{Co}\left(\mathrm{C}_{5} \mathrm{H}_{5}\right)_{2}$ and $\left(\mathrm{C}_{5} \mathrm{H}_{5}\right)_{2} \mathrm{Ni}$, only the parent ion is observed for all employed lamps. No other ions are detectable, setting the upper limit of their formation to 0.1 of that for the parent ion. In contrast, $\left(\mathrm{C}_{5} \mathrm{H}_{5}\right)_{2} \mathrm{Fe}$ and $\left(\mathrm{C}_{5} \mathrm{H}_{5}\right) \mathrm{Ni}(\mathrm{NO})$ undergo a single ligand elimination, losing cyclopentadienyl the former and the weaker-bonded nitrosyl ligand the latter. Evidently, the available photon energy is not enough to induce elimination of both ligands. The ratio of daughter ion to parent ion intensity is found to increase with increasing photon energy. Finally, the metal carbonyls $\mathrm{Co}(\mathrm{CO})_{3}(\mathrm{NO}), \mathrm{Cr}(\mathrm{CO})_{6}$ and $\mathrm{Mo}(\mathrm{CO})_{6}$ are found to suffer some ligand elimination upon photoexcitation/ionization. With increasing photon energy, new dissociation pathways open up (i.e., loss of additional ligand(s) occurs) and the degree of fragmentation increases (i.e., the signal of smaller ions is enhanced at the expense of the larger ones).

The cross-section of ionization could not be evaluated, because of the lack of appropriate standard. Based, however, on the measured light intensity and the total ion signal, its value near $120 \mathrm{~nm}$ ( $\mathrm{Kr}$ and $\mathrm{H}_{2}$ lamps) is estimated at $10^{-20} \mathrm{~cm}^{2}$ for all compounds studied herein, and it falls drastically with increasing wavelength.

\section{DISCUSSION}

Our purpose in this work was the assessment of the potential of photoionization spectroscopy in probing organometallic fragmentation in molecular beam-translational studies and in chemical vapor deposition processes. However, the results are interesting in their own right for their implications on the photophysics of organometallics. A discussion is also warranted by the paucity of the studies on the VUV photochemistry of organometallics.

To the best of our knowledge, only $\mathrm{Fe}(\mathrm{CO})_{5}$ has been studied ${ }^{8,9}$ systematically in the VUV region. By exciting at $11.6-11.8 \mathrm{eV}$, Hellner et al. ${ }^{8}$ observed that all energy in excess of that required for the dissociation step(s) is taken up by the iron atom as electronic excitation. Likewise, Horak and $\mathrm{Winn}^{9}$ found that modeling of the $\mathrm{Fe}^{*}$ fluorescence quantum yield over the 9-14 eV range required a "restricted-degreesof-freedom" statistical model.

Because of the limited set of our data, the nature of dissociation cannot be addressed in such detail herein. However, at least qualitatively, our results do not indicate strong dynamical bias in the VUV photoionization of metallocenes and metal carbonyls. For instance, nickelocene and cobaltocene both yield only parent ion peak, consistent with the fact that ionization strengthens the metal-ligand bond by removing the electron from a metal-cyclopentadiene antibonding orbital. ${ }^{10}$ In the case of ferrocene, some daughter ion formation is observed, which is similarly compatible with statistical fragmentation following electron removal from a predominantly metalligand bonding orbital. Finally, in the case of $\left(\mathrm{C}_{5} \mathrm{H}_{5}\right) \mathrm{Ni}(\mathrm{NO})$ and the metal carbonyls, we observe that with increasing photon energy, the fragmentation pattern is smoothly enhanced towards smaller fragments, as expected from statistical considerations. Thus, in the absence of reliable and accurate thermodynamic data enabling modeling 
of the ionic spectra, we conclude that no compelling evidence exists in support of non-statistical models. It is, however, possible that at the higher irradiation wavelengths employed in references 8 and 9, dynamical restrictions do come into play. Alternatively, the neutral dissociation pathways probed in these references may be subject to constraints that do not operate in the ionic one monitored herein.

With respect to the potential of VUV photoionization in probing photofragmentation of organometallics, the results obtained herein indicate that the technique offers definite advantages over electron-impact ionization. Electron-impact produces stronger signals, but at the expense of more extensive fragmentation. This is clearly demonstrated by comparing the photoinduced spectra with the corresponding electron-impact ones. In all cases, the electron-impact spectra, even at the lowest possible electron energy, are considerably more complex. The complexity of the electron impact versus photoionization spectra is most contrasting in the case of the larger complexes $\mathrm{Co}(\mathrm{CO})_{3}(\mathrm{NO}), \mathrm{Cr}(\mathrm{CO})_{6}$, and $\mathrm{Mo}(\mathrm{CO})_{6}$. For instance, electron bombardment on $\mathrm{Cr}(\mathrm{CO})_{6}$ (at a nominal electron energy of $20-30 \mathrm{eV}$ ) yields $\mathrm{Cr}(\mathrm{CO})_{6}^{+}$, $\mathrm{Cr}(\mathrm{CO})_{5}^{+}$(with approximately $\frac{1}{3}$ of the parent ion intensity), $\mathrm{Cr}(\mathrm{CO})_{4}^{+}\left(\frac{1}{6}\right.$ of parent ion peak) and some signal for the smaller fragments, whereas only $\mathrm{Cr}(\mathrm{CO})_{6}^{+}$appears with appreciable intensity in the photoionization spectra. Analogous observations have been made for the molemdenum complex.

Besides simplicity, VUV ionization affords additionally specificity in photofragment detection. Because the organometallic fragments derived from a specific parent molecule differ in their ionization potentials, they can be ionized selectively at different excitation wavelengths. In the case of the $\mathrm{Cr}(\mathrm{CO})_{\mathrm{x}}$ fragments, for instance, $\mathrm{Cr}(\mathrm{CO})_{6}$, ionizable at $8.42 \mathrm{eV}, \mathrm{Cr}(\mathrm{CO})_{5}$ at $8.24 \mathrm{eV}$ and $\mathrm{Cr}$ at $6.77 \mathrm{eV}$ (the ionization potential for the other chromium fragments are not known) ${ }^{15}$ can be selectively detected by the various lamps employed herein.

The detection of photofragments is complicated by the fact that any internal energy that they possess may contribute effectively to the ionization/fragmentation process. This problem is particularly accute for organometallics, because their photoexcitation in the UV region produces fragments with high internal excitation. However, this is a complication common to all ionization processes, including electron-impact one. Moreover, this problem can be resolved by exciting at lower wavelengths. In this case, comparison of the ion spectra obtained at various VUV wavelengths can set lower bounds on the internal energy of the species that are produced in the excimerlaser irradiation of the parent metal complex. Such information could, evidently, complement the information derived from the state-specific probing of the fragmented away ligands. ${ }^{1 a}$, le-f

Finally, the VUV approach seems to present advantages even in comparison with the IR transient absorption technique. Specifically, it is more general, in the sense that it is not limited to systems with well-defined and unobscured IR absorption bands. In contrast, the application of the photoionization detection requires only that the system of study absorbs at the exciting, ionization wavelength. This is generally true of most organometallics of interest, since they exhibit strong and essentially continuous absorption in the far UV and VUV region. ${ }^{11}$ 
On the negative side, the use of the photoionization approach is compromised by the lack of information on the ionization potentials of organometallic fragments. The most serious, however, problem in the use of the technique concerns its detection limits. The ion signal from VUV excitation was, at best, an order of magnitude smaller than the corresponding electron-impact signal (obtained with $0.04 \mathrm{~mA}$ electron emission current). It should be noted, however, that our current setup is not specifically designed for these experiments. Specifically, in our experiments, the absolute intensity at the ion source of the mass spectrometer is approximately $10^{7}-10^{9}$ quanta/sec, to be compared with a maximum reported intensity of $10^{14}$ quanta/sec for optimally operated lamps. ${ }^{7}$ With appropriate modifications, the signal-to-noise ratio is expected to improve by, at least, an order of magnitude, thereby enabling the implementation of the technique in photodissociation studies and LCVD monitoring.

For illustrative purposes, we consider the application of the VUV-ionization approach in the study of the photodesorption/fragmentation of $\mathrm{Mo}(\mathrm{CO})_{6}$ from cryogenic films. Briefly, the experiment entails the deposition of the compound on quartz substrate held at liquid nitrogen temperature and probing the translational energy of the fragments that desorb upon excimer-laser irradiation of the film. The fragments are interrogated in a quadrupole mass spectrometer housed in the second cell of a differentially-pumped system. Irradiation of the organometallic film results in a small signal for the parent molecule and large signals for $\operatorname{Mo}(\mathrm{CO})_{\mathrm{x}}, \mathrm{x}=5$ to 1 . The timeof-flight curves indicate that the species desorb with high velocities $\left(10^{4} \mathrm{~cm} / \mathrm{sec}\right.$, on the average). The extraction of distributions from these spectra is, however, complicated by the fact that except for $\mathrm{Mo}(\mathrm{CO})_{5}$, the spectra of all smaller fragments suffer contributions from the electron-impact dissociation of the larger metal-carbonyl species. For example, in the case of the $\mathrm{Mo}(\mathrm{CO})_{4}$ fragment, the electron-impact induced time-of-flight curve is found quite broader than the VUV-induced TOF curve. Tentatively, we ascribe the new curve to the exclusive ionization of $\mathrm{Mo}(\mathrm{CO})_{4}$ and the discrepancy between the spectra recorded by the two different ionization approaches to the contribution of the electron-impact dissociation of $\mathrm{Mo}(\mathrm{CO})_{5}$. Indeed, the difference between the two curves agrees with the $\mathrm{Mo}(\mathrm{CO})_{5}$ time-of-flight curve. Interestingly, the kinetic energies of the $\mathrm{Mo}(\mathrm{CO})_{4}$ species appear to depend sensitively on the deposited film thickness, whereas no such dependence is observed for $\mathrm{Mo}(\mathrm{CO})_{5}$. The dependency of $\mathrm{Mo}(\mathrm{CO})_{4}$ kinetic energy on film thickness suggests that film processes, i.e. secondary reactions, must be important for its desorption, in contrast to the pentacarbonyl species, which must be primary photodesorption product. A more detailed analysis of the results will appear elsewhere.

In conclusion, the VUV mass spectrometry seems a promising approach to assessing the photofragmentation patterns of organometallics. The technique affords higher selectivity and specificity than electron-impact ionization. We are currently developing a modified differentially-pumped system for monitoring fragmentation of organomatellics under conditions typical of LCVD processes. 


\section{References}

1. a) U. Ray, H. Q. Hou, Z. Zhang and M. Vernon. J. Chem. Phys., 90, 4248 (1989) b) E. Weitz, J. Phys. Chem., 91, 3945 (1987) c) J. P. Holland and R. N. Rosenfeld. J. Chem. Phys., 89, 7217 (1988) d) G. W. Tyndall and R. L. Jackson. J. Chem. Phys., 91, 2881 (1989) e) S. Georgiou and C. A. Wight. J. Phys. Chem., 94, 4935 (1990) f) I. M. Waller and J. W. Hepburn. J. Chem. Phys., 88, 6658 (1988) and references in these articles.

2. a) M. Georgopoulos, G. S. Fu, E. Hontzopoulos, and C. Fotakis. Mechanisms of Reactions of Organometallic Compounds with Surfaces (NATO ASI Series B, vol. 198, ed.: D. J. Cole-Hamilton, and J. O. Williams, Plenum Press, New York, 1989) and b) I. P. Herman. Chem. Rev., 89, 1323 (1989).

3. B. H. Weiller and E. R. Grant. J. Am. Chem. Soc., 109, 1051 (1987).

4. R. D. Levine and R. B. Bernstein. Molecular Reaction Dynamics and Chemical Reactivity (Oxford University Press, New York, 1987).

5. F. C. Fehsenfeld, K. M. Evenson, and H. P. Broida. Rev. Sci. Instrum., 36, 294 (1965).

6. H. Okabe. J. Opt. Soc. Amer., 54, 478 (1964).

7. D. Davis and W. Braun. Appl. Opt., 7, 2071 (1968).

8. L. Hellner, J. Masanet and C. Vermeil. Nouv. J. Chim., 3, 721 (1979).

9. D. V. Horak, and J. S. Winn. J. Phys. Chem., 87, 265 (1983).

10. A. Haaland. Acc. Chem. Res., 12, 415 (1979).

11. J. W. Rabalais, L. O. Werme, T. Bergmark, L. Karlson, M. Hussain, and K. Siegbahn. J. Chem. Phys., 57, 1185 (1972).

12. S. Evans, M. L. H. Green, B. Jewitt and A. F. Orchard. J. Chem. Soc. Faraday Trans., 2, 356 (1974).

13. S. Evans, M. F. Guest, I. H. Hillier and A. F. Orchard. J. Chem. Soc. Faraday Trans., 2, 417 (1974).

14. J. R. Chipperfield, J. C. R. Sneyd, D. E. Webster. J. Organomet. Chem., 178, 177 (1979).

15. Footnote 11 in reference $1 \mathrm{~d}$.

16. E. Winters and R. W. Kiser. Inorg. Chem., 4, 157 (1965). 